\title{
Do students conceptualize energy as a material substance?
}

\author{
M. E. Loverude, Department of Physics MH-611, \\ California State University Fullerton, P.O. Box 6866, Fullerton, CA 92834
}

On written problems and in interviews, some students predict mass changes associated with energy transfers. Explanations suggest that while some students may conceptualize energy as a substance with mass and volume, this idea is not consistently applied.

\section{INTRODUCTION}

In physics, energy is an abstract, nonmaterial quantity associated with the state of a system. Feynman states, "It is important to realize that in physics today, we have no knowledge of what energy is. We do not have a picture that energy comes in little blobs...it is an abstract thing in that it does not tell us the mechanism or the reasons for the various formulas." Arons notes that "'Energy' is not a substance, fluid, paint or fuel...we use this term to denote a construct-numbers calculated in a certain way, that are found by theory and experiment to preserve a remarkably similar relationship in very diverse physical phenomena." ${ }^{2}$ However, there is evidence to suggest that students conceptualize energy quite differently than do physicists. For example, studies on student understanding of thermal processes have suggested that student responses are consistent with the treatment of heat as a substance. $^{3} \quad$ Several researchers have suggested that these responses parallel the historical conception of heat as the "imponderable fluid" caloric, but have not explicitly investigated whether students conceive of heat as having mass. ${ }^{4}$

Other researchers have reported that students describe electric current as being 'used up' in a circuit ${ }^{5}$ and treat mechanical waves and sound as material objects. ${ }^{6}$ Chi, Slotta, and their collaborators suggested that these conceptual difficulties are due to ontological misclassification. ${ }^{7}$ In particular, they claim that students unwittingly classify physical concepts like 'heat' and 'current' as material substances as opposed to processes (or 'constraint-based interactions'), and that shifting between these ontological categories is quite difficult for students.
Some researchers have investigated the utility of teaching heat and temperature concepts to precollege students using an approach in which heat is treated as a semimaterial but massless substance. ${ }^{8}$

Motivation for study

In the current study, we sought to investigate the idea that students conceptualize energy as a material substance. Are student answers to physics questions consistent with the notion that a transfer of material takes place in a process that a physicist would describe as an energy transfer? To operationalize this question, we have taken mass as a defining property of material substances. A student who treats energy as a material substance might predict a mass increase as an object gains energy, or a mass decrease as an object loses energy. Therefore, we have investigated whether students predict changes in the mass of objects in energy transfer processes.

Of course, Einstein's equation $E=m c^{2}$ does predict mass changes with energy changes. Though these differences are very small, students may not have a sense of the order of magnitude of these differences. Therefore, we should be cautious about classification of student responses as 'misconceptions,' and pay close attention to student explanations. Only one student in the study has explicitly referred to Einstein's equation, but it may underlie other student responses and reflect a potentially productive student resource.

We have posed questions, in both written problems and in interview settings, in which students are asked to make predictions of the results of physical experiments and provide explanations of their predictions. Students were not asked explicitly whether energy is a substance with mass, or to define energy, but some discussions of this nature arose. 


\section{Context for research}

Students in the study were drawn from two courses at a public comprehensive university serving a diverse student population. The Course for Teachers is a physical science course for pre-service elementary school teachers. This course is taught in a labbased, guided inquiry format, meeting six hours each week. All students are nonscience majors planning to teach at the $\mathrm{K}-8$ level. The Survey Course is intended for non-science majors. The course meets three hours per week in a lecture format, with section sizes varying from 30 up to about 80 , and has an optional three-hour lab component. Both courses include a brief unit on mass, volume, and density, and a unit on energy, with emphasis on heat and temperature. Students in the two courses have similar backgrounds.

\section{STUDENT RESPONSES}

We have posed a series of problems during and after instruction in which students are asked about the mass of objects after energy transfers, or about the balancing behavior of heated objects. All written questions were open-ended and asked for an explanation. Specific problems are discussed below. Responses to all written problems are summarized in Table I. In all problems, many students answered that the mass of the objects in question would not change. Most of these students gave straightforward explanations that suggest a non-material conception of energy: "nothing was added to or taken out of the system." In the discussion below, we focus on answers predicting mass changes in order to investigate whether these answers reflect a material conception of energy.

Written question: Heated Balloon

The Heated Balloon question states that a sealed balloon filled with helium is heated and observed to expand. Students are asked whether the mass, volume, and density of the balloon increases, decreases, or remains the same. The problem states explicitly that "no gas may enter or leave the balloon." About $20 \%$ of students predicted a mass increase as the balloon was heated.
Students predicting a mass increase gave a variety of explanations. Many appear to reflect a failure to distinguish between mass and volume: "If the balloon expands that means it's getting bigger so therefore mass is increasing." However, many responses suggested an association of mass with energy. For example, one student wrote, "By the use of heat, energy is being transferred to the balloon. This transfer cause a transformation of energy, which is increasing the mass of the gas." Several students referred to microscopic particles in their explanations: "The mass of the gas increases because as heat is applied the electrons spread out more and more and thus makes the mass increase."

We have tested two other problems in which sealed systems are heated: a Ziploc bag of popcorn in a microwave oven, and a bottle of water heated on a hot plate. In each, more than a third of students predicted a mass change. In contrast to the balloon question, many predicted a mass decrease as the system was heated, often referring to density changes or the evaporation of water. Others have reported that some students do not conserve mass in phase changes. ${ }^{9}$

Written question: Balanced Blocks

The Balanced Blocks problem shows an initial situation in which two blocks are balanced. One block is heated to a final temperature much less than the block's melting point. Students are asked to sketch the position of the balance after the hot block is returned to its original position. In two sections $(N=105)$ of the Survey Course approximately half of the students drew the

Two plastic blocks A and B balance one another on an equal-arm balance. Block B is removed from the balance and heated gently. The final temperature of block B is much less than its melting point.

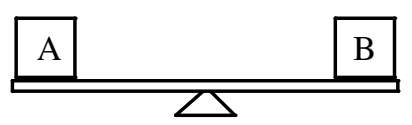

When block B has reached its final temperature, it is placed on the balance again in its original position. Sketch the resulting position of the balance. Explain briefly.

Figure: The Balanced Blocks problem. 


\begin{tabular}{|c|c|c|c|c|c|}
\hline & $\begin{array}{l}\text { Balanced } \\
\text { blocks }\end{array}$ & $\begin{array}{l}\text { Heated } \\
\text { balloon }\end{array}$ & $\begin{array}{l}\text { Popcorn } \\
\text { bag }\end{array}$ & $\begin{array}{c}\text { Heated } \\
\text { bottle }\end{array}$ & $\begin{array}{l}\text { Battery } \\
\text { mass }\end{array}$ \\
\hline & $N=105$ & $N=76$ & $N=58$ & $N=54$ & $N=262$ \\
\hline $\begin{array}{l}\text { Answers associating } \\
\text { energy transfer with : }\end{array}$ & $\begin{array}{l}2 \text { sections } \\
\text { Survey }\end{array}$ & $\begin{array}{l}2 \text { sections } \\
\text { Both }\end{array}$ & $\begin{array}{l}1 \text { section } \\
\text { Survey }\end{array}$ & $\begin{array}{l}2 \text { sections } \\
\text { Teachers }\end{array}$ & $\begin{array}{l}7 \text { sections } \\
\text { Both }\end{array}$ \\
\hline No change in mass & $52 \%$ & $76 \%$ & $66 \%$ & $43 \%$ & $57 \%$ \\
\hline Mass increase & $18 \%$ & $22 \%$ & $19 \%$ & $17 \%$ & $42 \%$ \\
\hline Mass decrease & $28 \%$ & $1 \%$ & $16 \%$ & $35 \%$ & $1 \%$ \\
\hline Other / blank & $2 \%$ & $1 \%$ & $0 \%$ & $5 \%$ & $0 \%$ \\
\hline
\end{tabular}

Table I: Student responses to written problems from several different semesters.

balance in the balanced position. Nearly $20 \%$ drew the hot block lower than the cold block, but more drew the hot block higher. Many of the students who suggested that the warmer block would be lower gave answers suggesting a mass increase with the heating process. For example, one wrote, "B has become heavier due to the heat accumulated inside the block," consistent with a material conception of energy. However, other students giving this answer explained it in terms of microscopic particles, referring to the increased motion of the particles ("I think that block B will be a little heavier because the particles will be moving faster than in block A") or to changes in the particles themselves ("The particles in B expanded causing it to be heavier than A.").

A significant fraction of responses invoked thermal expansion and then inappropriately connected the size increase to a change in mass. One such student wrote, "Heat causes objects to expand in mass creating more volume and therefore more weight in block $\mathrm{B}$, making the scale tip down on block B's side." Again, such responses may reflect a failure to distinguish between mass and volume, but it may also be that students interpret thermal expansion as reflecting the addition of material to an object.

Students supported the prediction that the hotter block would be higher with a variety of explanations. Some explanations were quite primitive: "I believe $B$ would be higher cause heat rises." In other cases, students gave explanations suggesting a conversion of matter to energy: "During heating some of the particles would have turned into energy and the weight of the block would have decreased." Many students made reference to changes in the material of the block, in properties like hardness and density, in the behavior of microscopic particles, or in combinations of these. For example, one wrote, "the particles are moving more in $\mathrm{B}$ (due to the heat), so there's more space between the particles, therefore decreasing the weight."

\section{Battery Mass}

We posed the Battery Mass question based on references in the research literature to student beliefs that current is consumed in electric circuits. The problem states that a student measures the mass of a flashlight battery, places the battery in a flashlight, and then leaves the flashlight turned on all night. Students are asked to compare the battery's mass in the morning to its initial mass and explain. This question has been used as an interview task as well as a written question.

In written versions in both courses, answers were divided primarily between the correct answer and the prediction that the mass of the battery would decrease. Nearly half of the students in the Course For Teachers predicted a decrease in mass, as compared to about $40 \%$ of those in the Survey Course. Students predicting a mass decrease often 
gave explanations very explicitly suggesting a material conception of energy. One student wrote, "Less than because the material within the battery decreased by loss of energy. When used up, that material decreased in volume." Several students also made references to the consumption of 'juice,' of electrons, or of various chemicals: "the electrons store in the battery has been used in the form of energy in order to create light. And as the energy is used (electrons) the mass of the battery decreases."

In the interview version of this problem several students predicted mass changes. One spontaneously connected this prediction to the phenomenon of thermal expansion: "My best guess is that they [batteries] would be lighter, because you're going to have a loss of energy to the light. I guess that would be the same reason why things expand, but I don't know." Another student offered an analogy: "Say the battery was like a glass of water. To make the flashlight work, you needed a certain amount of water...it used water, and the water would get lower and lower as you used it....at the end, an empty water glass would weigh less."

\section{SUMMARY AND FURTHER STUDY}

Preliminary results suggest that some student responses are consistent with a conception of energy as a material substance. However, the pattern of student responses is not simple, and students answer differently in different physical contexts.

Many student explanations refer to mass increases in connection with volume changes. These responses may reflect simple confusion between mass and volume or primitive responses in which 'more is more.' It may also be that the phenomenon of thermal expansion leads students to conclude that objects gain material as they are heated. Incorrect references to particles are common, consistent with reports that many students have incomplete or incorrect microscopic models of matter that lead to incorrect macroscopic predictions. ${ }^{10}$

Different tasks elicit significantly different response patterns. While answers to the Battery Mass and Heated Balloon problems appear to be consistent with the notion that an energy change results in corresponding change in mass, other heat transfer problems lead to more mixed results that are not consistent with the idea that students are conceptualizing energy as a material substance. For future research, we plan to test whether student answers to questions in different physical contexts are correlated. In addition, we will investigate whether a material concept of energy might be a productive resource for the development of the idea of conservation of energy.

\footnotetext{
${ }^{1}$ Feynman, R.P., R.B. Leighton, and M. Sands, The Feynman Lectures on Physics, Reading, MA: Addison-Wesley (1963).

${ }^{2}$ Arons, A.B., Development of Concepts of Physics, Reading, MA: Addison-Wesley (1965).

${ }^{3}$ See, for example, G. Erickson, "Childrens' conceptions of heat and temperature," Sci. Ed. 63, 221-230 (1979) and G. Erickson and A. Tiberghien, "Heat and temperature," in R. Driver, E. Guesne, and A. Tiberghien, eds., Children's Ideas in Science, Philadelphia, Open University Press (1985).

${ }^{4}$ For a contemporary description of the historical development of the caloric theory and Rumford's attempts to measure weight changes in heated objects, see ref. 2, p.413.

${ }^{5}$ See, for example, McDermott, L.C., and P.S. Shaffer, "Research as a guide for curriculum development: An example from introductory electricity, Part I: Investigation of student understanding," Am. J. Phys. 60, 994-1003 (1992).

${ }^{6}$ Linder, C., and G. Erickson, "A study of tertiary physics students' conceptualizations of sound," Int. J. Sci. Ed. 11, 491-501 (1989); M.C Wittman, "The object coordination class applied to wavepulses: Analysing student reasoning in wave physics," Int. J. Sci. Ed. 24, 97-118 (2002).

${ }^{7}$ M. Reiner, J.D. Slotta, M.T.H. Chi, and L.B. Resnick, "Naïve physics reasoning: A commitment to substance-based conceptions," Cogn. Instr. 18, 1-34 (2000); J.D. Slotta, M.T.H. Chi, and E. Joram, “Assessing students' misclassifications of physics concepts: An ontological basis for conceptual change," Cogn. Instr. 13, 373-400 (1995).

${ }^{8}$ M.C. Linn and N. Songer, "Teaching thermodynamics to middle school students: What are appropriate cognitive demands?" J. Res. Sci. Teaching 28, 835-918 (1991).

9 See, for example, R. Stavy, "Pupils' problems in understanding conservation of matter," Int. J. Sci. Ed. 12, 501-512 (1990).

${ }^{10}$ P.L. Lijnse, et. al., eds., Relating macroscopic phenomena to microscopic particles: A central problem in secondary science education, Utrecht: University of Utrecht (1989).
} 